\title{
Review Article \\ Physiological Role of Plasmacytoid Dendritic Cells and Their Potential Use in Cancer Immunity
}

\author{
Jorge Schettini ${ }^{1,2}$ and Pinku Mukherjee ${ }^{1}$ \\ ${ }^{1}$ Department of Immunology, Mayo Clinic College of Medicine, Mayo Clinic Arizona, 13400 E. Shea Blvd, \\ Scottsdale, AZ 85259, USA \\ ${ }^{2}$ Department of Biology, University of North Carolina at Charlotte, 9201 University City Blvd, \\ Charlotte, NC 28223, USA
}

Correspondence should be addressed to Jorge Schettini, jschetti@uncc.edu

Received 20 August 2008; Accepted 12 October 2008

Recommended by Michel Goldman

Dendritic cells (DCs) play a pivotal role in the control of innate and adaptive immune responses. They are a heterogeneous cell population, where plasmacytoid dendritic cells (pDCs) are a unique subset capable of secreting high levels of type I IFNs. It has been demonstrated that pDCs can coordinate events during the course of viral infection, atopy, autoimmune diseases, and cancer. Therefore, pDC, as a main source of type I IFN, is an attractive target for therapeutic manipulations of the immune system to elicit a powerful immune response against tumor antigens in combination with other therapies. The therapeutic vaccination with antigen-pulsed DCs has shown a limited efficacy to generate an effective long-lasting immune response against tumor cells. A rational manipulation and design of vaccines which could include DC subsets outside "Langerhans cell paradigm" might allow us to improve the therapeutic approaches for cancer patients.

Copyright (C) 2008 J. Schettini and P. Mukherjee. This is an open access article distributed under the Creative Commons Attribution License, which permits unrestricted use, distribution, and reproduction in any medium, provided the original work is properly cited.

\section{INTRODUCTION}

There is not a clear answer why tumor immunity is not effectively mounted in most tumor-bearing hosts. Early mouse studies, as well as clinical experience, indicate that the immune system can recognize and reject tumors [1-11]. On the contrary, immune-deficient mice and patients have an augmented incidence of cancer which suggests a relevant role for the immune system $[12,13]$. Immunotherapeutic protocols based on these findings have been developed; however, the results are variable and limited [14-19]. As observed in melanoma and other tumors, there is an absence of specific cytotoxic T lymphocytes (CTLs) expansion in cancer patients. This suggests that tumor-antigens may not overcome the threshold on the surface of DCs needed to trigger CTL proliferation (passive factor). In addition, immunoregulatory factors are involved in downregulating $\mathrm{T}$ cell proliferation and inducing $\mathrm{T}$ regulatory cells (active factors), secreted by tumor cells [14]. Thus, DCs play a critical role in inducing and regulating the immune responses $[20,21]$.
DCs constitute a heterogeneous cell population, which are classified according to cluster of differentiation (CD) expression, functionality, and localization, playing a pivotal role in the control of innate and adaptive immune responses [22]. Generally, DCs' life cycle is based on a model commonly referred to as the "Langerhans cells paradigm" [23]. Immature DCs are strategically located in peripheral and interstitial spaces of most tissues, and from their location, and always in surveillance mode, DCs constitutively take up antigens from the environment, which will be associated with the MHC molecules. Coordinately, DCs mature by cessation of phagocytosis and endocytosis and move toward the draining lymphoid nodes (LNs) due to upregulation of chemokine receptor CCR7, thereby, acquiring responsiveness to a chemotactic gradient of CCL21(-Leu/-Ser) and CCL19 expressed by initial and terminal lymphatic vessels and by mature DCs, respectively [24, 25].

After arriving at the draining lymphoid nodes, DCs are able to present antigens in the context of MHC and costimulatory molecules to antigen-specific $\mathrm{T}$ cells. This induces a cellular immune response which drives $\mathrm{T}$ cells 
to differentiate to effectors cells $[26,27]$. Moreover, DCs are important in starting adaptive and innate immunity, by activating naïve and memory $B$ cells, natural killer, and natural killer T cells [28-31].

Due to the antigen capturing and presenting properties of DCs, ex vivo delivery of tumor-antigen to DCs has been used as a strategy to guarantee successful antigen presentation to $\mathrm{T}$ cells [14]. However, the efficacy of this approach to therapeutic vaccination has been limited in both preclinical and clinical settings [19, 32]. This suggests that we need to better understand and refine the parameters to establish the optimal conditions for vaccination against cancer.

Recent progress in the identification of distinct DC subsets has been done. Analysis of the DC population in several lymphoid organs has shown a considerable heterogeneity, where some subsets of DCs follow the "Langerhans cell paradigm", but not all of them [33, 34]. Unfortunately, the heterogeneity of the human DC network is poorly understood compared with the mouse DC network. At present, there are two main pathways of differentiation in mouse DCs. The myeloid pathway generates two subsets: Langerhans cells and interstitial DCs, whereas the lymphoid pathway generates plasmacytoid DCs (pDCs) [22, 28, 35]. In contrast to the many studies in mouse DCs, there are very few studies on mature human DCs from tissue. Human blood DCs are heterogeneous in their expression of markers, but this may reflect differences in the activation or maturation states of DCs rather than separate lineages [36]. However, from in vitro studies, it is possible to deduce pathways of human dendritic cell development. Similar to mouse DCs, the myeloid pathway in humans generates Langerhans cells and interstitial DCs. Blood monocytes, named precursors DC1 ( $\mathrm{pDC} 1$ ), are the most commonly used precursor cells for generating human DCs in culture. In the presence of GM-CSF and IL-4, pDC1 can generate DCs called DC1. Maturation of these cells is achieved by stimulating cytokines or microbial products [22, 37-39]. The human lymphoid pathway also generates pDCs, termed pDC2. These cells are type I IFN producing cells (IPCs) and they were discovered before their mouse counterparts. The pDC2 responds to viral and microbial stimuli by producing type I IFNs [35]. Both human and mouse pDCs can be maturated with bacterial stimuli or viruses. Upon maturation, human pDC2, named DC2, lacks typical myeloid markers, such as its precursor, but displays the characteristic of mature DCs $[40,41]$.

Although most studies have focused on the role of pDCs in antiviral immunity, several new lines of evidence have suggested that pDCs are also involved in tumor immunity, as well as in promoting peripheral tolerance [4247]. Interestingly, pDCs can synthesize large amount of functional indoleamine 2,3-dioxygenase (IDO), which requires autocrine release of type I IFN, upon Toll-like receptor-9 (TLR9) and CD200R ligands stimulation. IDO secretion by pDCs promotes T-cell death at T-cell areas of secondary lymphoid organs. Notably, through the upregulation of inducible T-cell costimulator ligand (ICOSL), pDCs have the ability to generate regulatory $\mathrm{T}$ cells $[48,49]$. Gathering together, this evidence suggests that pDCs represent a key effector cell in both innate and adaptive immunity regulation $[35,50-53]$. In this review, we focus on the characterization, physiology, and potential roles of pDCs in the antitumor responses.

\section{DIFFERENTIATION AND TRAFFICKING PATTERNS OF PDCs}

The growth factor fms-like tyrosine kinase 3 ligand (FLT3L) has been described as a key differentiation and trafficking factor for human and mouse pDCs from hematopoietic progenitor cells (HPCs). FLT3-L injection in humans causes an increase of both myeloid DCs (mDCs) and pDCs in the blood. In mice, FLT3-L injection induces the generation of $\mathrm{mDCs}$ and $\mathrm{pDCs}$ in blood, lymphoid tissues, liver, and lung [54-59]. In vitro, $\mathrm{mDC}$ and $\mathrm{pDCs}$ can be generated from FLT3-L-supplemented BM culture system [60, 61]. Recently, Fancke et al. have also shown that M-CSF is capable of driving pDCs from bone marrow precursor cells in vitro and in vivo [62].

pDCs account for less than $1 \%$ of total peripheral blood mononuclear cells (PBMCs) and can be isolated through removal of lineage-positive cells and $\mathrm{CD}_{123}{ }^{+}$(IL-3R). The identification of two markers on human (BDCA-2 and BDCA-4) and one in the mouse (PDCA-1) has facilitated the isolation of pDCs from PBMC or lymphoid organs by positive selection with magnetic beads coupled with specific monoclonal antibodies $[63,64]$.

In human and mice, pDCs have been found circulating in the blood and cord blood of neonates [65-67]. Interestingly, human pDCs have been found in fetal liver, thymus, and bone marrow suggesting that pDCs develop from $\mathrm{CD} 34^{+}$ human stem cells (HSCs) within these primary lymphoid tissues [68]. Moreover, pDCs can be located in lymphoid nodes, spleen, tonsils, and Peyer's patches.

Similar to $\mathrm{B}$ and $\mathrm{T}$ cell migration patterns, $\mathrm{pDCs}$ leave the bone marrow and migrate into the $\mathrm{T}$ cell rich areas of the secondary lymphoid tissues, through highendothelial venules (HEVs) in the lymph nodes, mucosaassociated lymphoid tissues, and through marginal zones of the spleen under steady-state conditions [69-73]. This unique migration pattern of pDCs among DCs appears to be connected with their expression of CD62L and CCR7, which allows the pDCs ligate L-selectin ligands expressed by HEV and chemokines CCL19 and CCL21 expressed by HEVs and stromal cells within the T-cell rich areas, respectively $[73,74]$.

The expressions of chemokine receptors on circulating blood mDCs and pDCs are similar. However, the level of CCR5, CCR7, and CXCR3 expressions is clearly divergent in these two subsets, being higher on pDCs than on mDCs [74]. Among these two subsets, pDCs are also the only to migrate in response to the homeostatic chemokine SDF1/CXCL12, the ligand of CXCR4, which is expressed on dermal endothelial cells, in HEVs of lymphoid nodes, and in malignant cells [44]. This evidence suggests that pDCs may reach lymph nodes using CXCR4, and also explains their 
fundamental localization in the secondary lymphoid organs $[70]$.

Interestingly, human pDCs have been found to infiltrate primary and malignant melanoma, head and neck carcinoma, ovarian carcinoma, and breast cancer [42-46, 75], as well as cutaneous inflammatory lesions, which may be dependent on their ability to express CLA, which binds to E-selectin on dermal endothelial cells and may enhance their recruitment to the inflammatory site [76].

\section{ACTIVATION OF PLASMACYTOID DCS}

Virtually, all cell types are able to produce type I IFNs in response to viral exposure. The amount, kinetics, and types of IFN will depend on the cell type. However, pDCs are considered the professional type I IFN producing cells [35]. pDCs can produce 100-1000 times more type I IFN than the other blood cell types upon activation [35], or the equivalent of $10 \mathrm{pg} / \mathrm{cell}$ [77]. Myeloid DCs can also secrete type I IFN in response to RNA viruses, but less efficiently than pDCs [78].

It is important to note that not all viruses can activate pDCs to produce IFNs. Also, pDCs do not require to be infected to secrete type I IFN $[79,80]$. Once secreted, type I IFNs induce MxA, an IFN $\alpha$-inducible intracellular protein [75], oligoadenylate synthetase, and double-stranded RNA-(dsRNA-)-dependent protein kinase (PKR). Together, these proteins have the biological role in inducing cellular resistance by blocking viral replication, and, therefore, viral spread [81].

Moreover, type I IFN modulates several aspects of the immune response, including $\mathrm{pDC}$ survival, mDCs differentiation [82], modulation of Th1 and $\mathrm{CD}^{+} \mathrm{T}$-cell responses, cross-presentation and cross-priming independent of $\mathrm{CD}^{+}$ T helper cells [83], upregulation of MHC and costimulatory molecules, activation of NK cells, and induction of primary antibody responses [84].

pDC activation with pathogens or oligodeoxynucleotides (ODNs) with multiple unmethylated CpG dinucleotides induces the secretion of several other cytokines and chemokines, such as TNF $\alpha$, IL-1, and IL-6. In mouse, but not in humans, pDCs have the capacity to synthesize bioactive IL-12, although this capacity still remains controversial [8587]. Virally, stimulated pDC produces chemokines, such as CCL3 (MIP-1a), CCL4 (MIP-1b), CCL5 (RANTES), CXCL8 (IL-8), and CXCL10 (IP-10) which stimulate Th1, and NK cells homing to site of infection through IP-10 and CCL4, respectively $[88,89]$.

\section{REGULATION OF TYPE I IFN SYNTHESIS ON pDCS}

This unique subset of DCs can secrete type I IFNs faster than other cells to a wider range of viral and nonviral stimuli. Moreover, pDCs express a broader profile of IFNA genes than other antigen-presenting cells (APCs). In humans, the type I IFN family consists of 13 IFN $\alpha$ subtypes, one IFN $\beta$, one IFN- $\omega$, one IFN- $\kappa$, and one IFN- $\tau$. IFN $\alpha 1$ is the major subtype expressed by pDCs, but other subtypes are also secreted, including IFN $\alpha 2,-\alpha 5,-\alpha 8,-\alpha 10$, and $-\alpha 14$ and a recently described family of IFN $\lambda 1-3$ (also named IL-29, IL28A, and IL-28B, resp.) $[90,91]$.

What makes pDCs synthesize type I IFN faster than other cells? Recently, it has been shown that transcription factors of the family of interferon regulatory factors (IRFs) play an important role in the regulation of interferon gene transcription. Nine mammalian IRF family members have been identified to guide the induction of IFN production, as well as to regulate and differentiate various cells types [92]. Expression of IRF- 3 supports induction of IFN $\beta$ and IRF- 5 or IRF-7 is sufficient to stimulate IFN $\alpha$ genes expression. Unlike other cells, pDCs have been shown to express constitutively higher levels of IRF-5, -7, and -8 mRNA, which might explain why this particular subset of DCs secrete faster and large quantities of type I IFNs than other cell types $[93,94]$.

\section{DIFFERENTIAL EXPRESSION AND FUNCTION OF TLRs IN pDCs}

This unique ability of pDCs to secrete large amounts of type I IFN depends on cellular receptors able to sense several types of nucleic acid. TLR is a family of 11 pattern recognition receptors (PRRs) which mediate the recognition of many pathogens through the detection of distinct pathogenassociated molecular patterns (PAMPs) $[95,96]$.

pDCs and mDCs each has a different TLR expression profile. In humans, mDCs can express TLR-1, -2, -3, -4, $-5,-7$, and -8 , while pDCs express mainly TLR7 and -9 [97, 98]. Uniquely, TLR-7, -8, and -9 detect PAMPs in endosomal/lysosomal compartments followed by acidification $[99,100]$. Transcriptional regulation of IFN $\beta$ and IFN $\alpha$ genes on pDCs is controlled mainly by IRF-3 and IRF-5/7. IRF- 3 can be activated by TLR-3 and TLR-4, but there is no evidence of this pathway on pDCs. Instead, IRF-7 has a constitutively high expression in pDCs and it is recruited by myeloid differentiation primary response gene 88 (MyD88) through the adaptor molecule TRAF6 when TLR-7 or -9 is triggered [101].

Many studies have shown that exposure to synthetic TLR-7 or -9 agonists (e.g., imidazoquinoline, CpG ODN) induces $\mathrm{pDCs}$ to secrete IFN $\alpha$ and proinflammatory cytokines (IL-8 and TNF $\alpha$ ), maturation, which heighten their T-cell stimulatory capacity [97, 102-104].

Interestingly, endogenous antigens, such as DNA from necrotic cells, may be taken up by pDCs and signal through TLR-9 in autoimmune diseases [105]. TLR-9 agonist has a therapeutic potential and it has been used to induce innate and adaptive immune responses. Synthetic TLR-9 agonists are currently being tested in multiple phase II and phase III human clinical trial as adjuvants to cancer vaccine and in combination with conventional chemotherapy and others protocols [106-108].

\section{PDCs CAN LINK INNATE AND ADAPTIVE IMMUNITY VIA TYPE I IFNs}

There are abundant studies in human and mice showing the importance of type I IFN to regulate inflammation 
TABLE 1

\begin{tabular}{|c|c|c|c|c|}
\hline Tumor & System & DC source & Protocol & References \\
\hline $\begin{array}{l}\text { EG7 T-cell } \\
\text { lymphoma }\end{array}$ & Murine & $\begin{array}{l}\text { Expanded in vivo (FLt3L), } \\
\text { and sorted from BM }\end{array}$ & $\begin{array}{l}\text { CpG-activated } \\
\text { OVAp-pulsed pDCs/mDCs }\end{array}$ & $\begin{array}{l}\text { Lou et al. [109] } \\
(2007)\end{array}$ \\
\hline $\begin{array}{l}\text { K17-35-OVA } \\
\text { melanoma }\end{array}$ & Murine & $\begin{array}{l}\text { Isolated TIDCs from } \\
\text { K17-35 melanoma }\end{array}$ & OVA-pulsed TIDCs & $\begin{array}{l}\text { Preynat-Seauve } \\
\text { et al. [110] (2006) }\end{array}$ \\
\hline $\begin{array}{l}\text { C26 colon } \\
\text { Carcinoma } \\
\end{array}$ & Murine & $\begin{array}{l}\text { Isolated TIDCs from C26 } \\
\text { tumor }\end{array}$ & $\begin{array}{l}\text { TIDCs activated with CpG } \\
+ \text { anti-IL-10R (i.p.) }\end{array}$ & $\begin{array}{l}\text { Vicari et al. [111] } \\
(2002)\end{array}$ \\
\hline M3 Melanoma & Murine & ( & $\begin{array}{l}\text { Topical application } \\
\text { Imiquimod }\end{array}$ & $\begin{array}{l}\text { Palamara et al. } \\
{[46](2004)}\end{array}$ \\
\hline $\begin{array}{l}\text { Melanoma cell } \\
\text { lines }\end{array}$ & Human & Sorted from PBMC & $\begin{array}{l}\text { pDCs activated with } \\
\text { CD40L-transfected J558 }\end{array}$ & $\begin{array}{l}\text { Salio et al. [42] } \\
(2003)\end{array}$ \\
\hline $\begin{array}{l}\text { Melanoma } \\
\text { stage IIIb/c, IV }\end{array}$ & Human & - & CpG-7909 (s.c.) (ProMune) & $\begin{array}{l}\text { Pashenkov et al. } \\
\text { [112] (2006) }\end{array}$ \\
\hline
\end{tabular}

DCs, dendritic cells; pDCs, plasmacytoid DCs; BM, bone-marrow; OVAp, OVA peptide; TIDCs, tumor-infiltrating DCs (myeloid and plasmacytoid); PBMC, peripheral blood mononuclear cells.

and link innate and adaptive immunity [113-115]. IFN $\alpha$ and $-\beta$ are considered as important components of innate immunity together with their well-known antiviral activity [114]. Type I IFN released by human pDCs activates NK cell cytolytic activity, and also induces IFN $\gamma$ production in NK cells through IL-12 secretion [116, 117]. Although with different molecular mechanisms in human and mice, type I IFN secreted by pDCs, upon stimulation, can affect Tcell functions. Thus, activated pDCs can induce T cells to make IL-10 and IFN $\gamma[113,118]$, and also induce a Th1 polarization [119]. It has also been reported that type I IFN can induce early activation markers (CD69) on T cells, long-term survival [120], and generation of a long-term antitumor immune response [121]. Recently, several studies have provided important evidence for a role of type I IFN in the differentiation of the Th1 subset [122], in the generation and activity of CTLs, as well as in supporting in vivo proliferation and survival of T cells $[123,124]$. Altogether, these studies have led to the recognition of an important role of this cytokine in linking innate with adaptive immunity $[115,125]$.

On the other hand, murine pDCs can also inhibit certain mDCs functions. Upon infection, mice pDCs are the primary source of IFN $\alpha$ and IL-12, and type I IFNs they produce inhibit the synthesis of IL- 12 from mDCs, a critical immunostimulatory cytokine of the T-cell-mediated immunity [79]. In human, the production of IL- 12 by pDCs is still controversial, but some studies claimed the contrary $[98,126]$.

Interestingly, pDCs are critical for the generation of plasma cells and antibody responses. It appears that the depletion of pDCs from human blood abrogates the secretion of IgGs in response to viral infection. Furthermore, activated pDCs can induce activated B cells to differentiate plasma cells. Through Type I IFN and IL6 secreted by pDCs, B cells are induced to develop into plasmablast and differentiate into antibody-secreting plasma cells [29].

\section{PLASMACYTOID DCS AND THEIR ROLE IN CANCER IMMUNITY}

Before the maturation of pDCs, they have a poor Tcell stimulation capacity. Early experiments reported that CD40L in combination with IL-3-stimulated pDCs develop into a functionally distinct DCs type that promotes the development of IL-4-secreting Th2 cells [40]. Also, pDCs can prime Th1 or Th0 allogeneic responses [118, $127,128]$. Furthermore, pDCs mature following exposure to influenza virus and exhibited an equivalent efficiency to expand the repertoire of anti-influenza virus cytotoxic $\mathrm{T}$ lymphocytes and $\mathrm{Th} 1 \mathrm{CD}^{+} \mathrm{T}$ cells [104, 129].

It is clear now that immature mDCs and pDCs infiltrate solid tumor and lack the ability to induce T-cell activation [75]. However, they still present tumor antigens and induce IL-10-producing $\mathrm{CD} 4^{+} / \mathrm{CD} 25^{+}$regulatory $\mathrm{T}$ cells that inhibit antitumor immunity [130]. Nevertheless, using an anti-IL$10 \mathrm{mAb}$ and $\mathrm{CpG}$ ODN, it is possible to induce a robust antitumor CTL response and tumor rejection in vivo [111]. Recently, murine pDCs have been described to have the ability to elicit in vivo, in naïve mice, an antigen-specific $\mathrm{CD}^{+} \mathrm{T}$ cell response against endogenous antigens, as well as exogenous peptides, but not against exogenous antigens, and were capable of protecting mice from tumor challenge [131].

It has also been reported that human tumor antigens pulsed $\mathrm{pDCs}$ in vitro can prime IFN $\gamma$-secreting melanoma-specific CTLs [42]. Synergy among DC subsets has not been fully explored in the development of antitumor immunity. An interesting study has shown that immunizations with a mixture of matured pDCs plus mDCs resulted in increased levels of antigen-specific CD8 ${ }^{+}$ $\mathrm{T}$ cells and an enhanced antitumor response compared with immunization with either dendritic cell subset alone [109]. Altogether, these studies suggest that it is possible to re-establish and/or maximize an antitumor immune 
response when pDCs are taken in the regimen [132-137] (Table 1).

\section{CLINICAL SIGNIFICANCE OF pDCs}

There is evidence that pDCs are located in several types of tumors: head and neck cancer, ovarian cancer, primary melanoma cancer, and breast cancer [42-46, 75]. Secreted factors by tumor cells may inhibit pDCs function, such as $\operatorname{TGF} \beta$, vascular endothelial growth factor $\beta(\operatorname{VEGF} \beta)$, and IL-10.

On the contrary, other studies have reported that pDCs and tumor-infiltrating DC (TIDC) are functional and fully competent APCs. Isolation of TIDC showed an intermediate maturation phenotype and the capacity to take up particles, as well as produce IL-12 and maintain its migratory capacity. Infiltrating pDCs are capable of producing IFN $\alpha$, as well as inducing complete regression or significant reduction of melanomas after a topically treatment of imiquimod (a small synthetic immune response modifier recognized by TLR7) $[46,110,138,139]$. In addition, intratumoral stimulation of pDCs with TLR7 and -9 agonists has been successfully used in the clinic to treat basal cell carcinoma, human papillomavirus-infected warts, and condylomata accuminata $[140,141]$. TLR signaling on pDCs can be used to induce type I IFNs and possibly protect DCs from tumor-derived inhibitory factors (such as VEGF $\beta$ or IL-10), as well as support T-cell survival, therefore, improving vaccination efficacy [112, 142-147].

Thus, it will be critical to evaluate if stimulation of pDCs may overcome tumor-mediated inhibitory effects and can enhance a local antitumor immunity.

\section{CONCLUSIONS}

DCs are a heterogeneous cell population, where plasmacytoid dendritic cells (pDCs) are a unique subset capable of secreting high levels of type I IFNs. It has been demonstrated that pDCs can coordinate events during the course of viral infection, atopy, autoimmune diseases, and cancer. Therefore, pDCs as a main source of type I IFN is an attractive target for therapeutic manipulations of the immune system to elicit a powerful immune response against tumor antigens in combination with others therapies.

A rational manipulation and design of vaccines which could include DCs subsets outside "Langerhans cell paradigm" might allow us to improve the therapeutic approaches for cancer patients.

\section{ACKNOWLEDGMENTS}

The authors would like to thank Teresa Tinder for helpful review of this manuscript. This work was funded by Pancreas SPORE Grant (P50 CA102701).

\section{REFERENCES}

[1] K. Inaba, J. P. Metlay, M. T. Crowley, and R. M. Steinman, "Dendritic cells pulsed with protein antigens in vitro can prime antigen-specific, MHC-restricted T cells in situ," The Journal of Experimental Medicine, vol. 172, no. 2, pp. 631640, 1990.

[2] T. Sornasse, V. Flamand, G. de Becker, et al., "Antigen-pulsed dendritic cells can efficiently induce an antibody response in vivo," The Journal of Experimental Medicine, vol. 175, no. 1, pp. 15-21, 1992.

[3] L. Zitvogel, J. I. Mayordomo, T. Tjandrawan, et al., "Therapy of murine tumors with tumor peptide-pulsed dendritic cells: dependence on T cells, B7 costimulation, and T helper cell 1associated cytokines," The Journal of Experimental Medicine, vol. 183, no. 1, pp. 87-97, 1996.

[4] C. M. Celluzzi, J. I. Mayordomo, W. J. Storkus, M. T. Lotze, and L. D. Falo Jr., "Peptide-pulsed dendritic cells induce antigen-specific, CTL-mediated protective tumor immunity," The Journal of Experimental Medicine, vol. 183, no. 1, pp. 283-287, 1996.

[5] S. K. Nair, D. Snyder, B. T. Rouse, and E. Gilboa, "Regression of tumors in mice vaccinated with professional antigenpresenting cells pulsed with tumor extracts," International Journal of Cancer, vol. 70, no. 6, pp. 706-715, 1997.

[6] F. Fu, Y. Li, S. Qian, et al., "Costimulatory molecule-deficient dendritic cell progenitors (MHC class II+, CD80(dim), CD86-) prolong cardiac allograft survival in nonimmunosuppressed recipients," Transplantation, vol. 62, no. 5, pp. 659-665, 1996.

[7] J. Ma, W. J. Urba, L. Si, Y. Wang, B. A. Fox, and H.-M. $\mathrm{Hu}$, "Anti-tumor $\mathrm{T}$ cell response and protective immunity in mice that received sublethal irradiation and immune reconstitution," European Journal of Immunology, vol. 33, no. 8, pp. 2123-2132, 2003.

[8] W. Asavaroengchai, Y. Kotera, and J. J. Mulé, "Tumor lysate-pulsed dendritic cells can elicit an effective antitumor immune response during early lymphoid recovery," Proceedings of the National Academy of Sciences of the United States of America, vol. 99, no. 2, pp. 931-936, 2002.

[9] T. Boon, J.-C. Cerottini, B. van den Eynde, P. van der Bruggen, and A. van Pel, "Tumor antigens recognized by T lymphocytes," Annual Review of Immunology, vol. 12, no. 1, pp. 337-365, 1994.

[10] P. van der Bruggen, C. Traversari, P. Chomez, et al., "A gene encoding an antigen recognized by cytolytic $\mathrm{T}$ lymphocytes on a human melanoma," Science, vol. 254, no. 5038, pp. 1643-1647, 1991.

[11] S. A. Rosenberg, Y. Kawakami, P. F. Robbins, and R.-F. Wang, "Identification of the genes encoding cancer antigens: implications of cancer immunotherapy," Advances in Cancer Research, vol. 70, pp. 145-177, 1996.

[12] A. S. Dighe, E. Richards, L. J. Old, and R. D. Schreiber, "Enhanced in vivo growth and resistance to rejection of tumor cells expressing dominant negative IFN $\gamma$ receptors," Immunity, vol. 1, no. 6, pp. 447-456, 1994.

[13] S. Euvrard, J. Kanitakis, and A. Claudy, "Skin cancers after organ transplantation," The New England Journal of Medicine, vol. 348, no. 17, pp. 1681-1691, 2003.

[14] I. D. Davis, M. Jefford, P. Parente, and J. Cebon, "Rational approaches to human cancer immunotherapy," Journal of Leukocyte Biology, vol. 73, no. 1, pp. 3-29, 2003.

[15] O. J. Finn, "Cancer vaccines: between the idea and the reality," Nature Reviews Immunology, vol. 3, no. 8, pp. 630-641, 2003.

[16] S. Antonia, J. J. Mulé, and J. S. Weber, "Current developments of immunotherapy in the clinic," Current Opinion in Immunology, vol. 16, no. 2, pp. 130-136, 2004. 
[17] E. C. Hsueh and D. L. Morton, "Antigen-based immunotherapy of melanoma: canvaxin therapeutic polyvalent cancer vaccine," Seminars in Cancer Biology, vol. 13, no. 6, pp. 401407, 2003.

[18] V. K. Sondak and J. A. Sosman, "Results of clinical trials with an allogeneic melanoma tumor cell lysate vaccine: melacine ${ }^{\circledR}$," Seminars in Cancer Biology, vol. 13, no. 6, pp. 409-415, 2003.

[19] P. Mukherjee, C. S. Madsen, A. R. Ginardi, et al., "Mucin 1specific immunotherapy in a mouse model of spontaneous breast cancer," Journal of Immunotherapy, vol. 26, no. 1, pp. 47-62, 2003.

[20] S. Yamazaki, T. Iyoda, K. Tarbell, et al., "Direct expansion of functional $\mathrm{CD} 25^{+} \mathrm{CD} 4^{+}$regulatory $\mathrm{T}$ cells by antigenprocessing dendritic cells," The Journal of Experimental Medicine, vol. 198, no. 2, pp. 235-247, 2003.

[21] H. Jonuleit, E. Schmitt, G. Schuler, J. Knop, and A. H. Enk, "Induction of interleukin 10-producing, nonproliferating $\mathrm{CD}^{+} \mathrm{T}$ cells with regulatory properties by repetitive stimulation with allogeneic immature human dendritic cells," The Journal of Experimental Medicine, vol. 192, no. 9, pp. 12131222, 2000.

[22] K. Shortman and Y.-J. Liu, "Mouse and human dendritic cell subtypes," Nature Reviews Immunology, vol. 2, no. 3, pp. 151$161,2002$.

[23] R. M. Steinman, "The dendritic cell system and its role in immunogenicity," Annual Review of Immunology, vol. 9, pp. 271-296, 1991.

[24] I. Mellman and R. M. Steinman, "Dendritic cells: specialized and regulated antigen processing machines," Cell, vol. 106, no. 3, pp. 255-258, 2001.

[25] G. J. Randolph, V. Angeli, and M. A. Swartz, "Dendriticcell trafficking to lymph nodes through lymphatic vessels," Nature Reviews Immunology, vol. 5, no. 8, pp. 617-628, 2005.

[26] E. Ingulli, A. Mondino, A. Khoruts, and M. K. Jenkins, "In vivo detection of dendritic cell antigen presentation to CD4 ${ }^{+}$ T cells," The Journal of Experimental Medicine, vol. 185, no. 12, pp. 2133-2141, 1997.

[27] J. M. Austyn, "New insights into the mobilization and phagocytic activity of dendritic cells," The Journal of Experimental Medicine, vol. 183, no. 4, pp. 1287-1292, 1996.

[28] C. Caux, C. Massacrier, B. Vanbervliet, et al., "CD $34^{+}$ hematopoietic progenitors from human cord blood differentiate along two independent dendritic cell pathways in response to granulocyte-macrophage colony-stimulating factor plus tumor necrosis factor $\alpha$ : II. Functional analysis," Blood, vol. 90, no. 4, pp. 1458-1470, 1997.

[29] G. Jego, A. K. Palucka, J.-P. Blanck, C. Chalouni, V. Pascual, and J. Banchereau, "Plasmacytoid dendritic cells induce plasma cell differentiation through type I interferon and interleukin 6," Immunity, vol. 19, no. 2, pp. 225-234, 2003.

[30] N. C. Fernandez, A. Lozier, C. Flament, et al., "Dendritic cells directly trigger NK cell functions: cross-talk relevant in innate anti-tumor immune responses in vivo," Nature Medicine, vol. 5, no. 4, pp. 405-411, 1999.

[31] N. Kadowaki, S. Antonenko, S. Ho, et al., "Distinct cytokine profiles of neonatal natural killer $\mathrm{T}$ cells after expansion with subsets of dendritic cells," The Journal of Experimental Medicine, vol. 193, no. 10, pp. 1221-1226, 2001.

[32] S. A. Rosenberg, J. C. Yang, and N. P. Restifo, "Cancer immunotherapy: moving beyond current vaccines," Nature Medicine, vol. 10, no. 9, pp. 909-915, 2004.
[33] K. Shortman and S. H. Naik, "Steady-state and inflammatory dendritic-cell development," Nature Reviews Immunology, vol. 7, no. 1, pp. 19-30, 2007.

[34] J. A. Villadangos and W. R. Heath, "Life cycle, migration and antigen presenting functions of spleen and lymph node dendritic cells: limitations of the Langerhans cells paradigm," Seminars in Immunology, vol. 17, no. 4, pp. 262-272, 2005.

[35] Y.-J. Liu, "IPC: professional type 1 interferon-producing cells and plasmacytoid dendritic cell precursors," Annual Review of Immunology, vol. 23, no. 1, pp. 275-306, 2005.

[36] D. N. J. Hart, "Dendritic cells: unique leukocyte populations which control the primary immune response," Blood, vol. 90, no. 9, pp. 3245-3287, 1997.

[37] A. Bender, M. Sapp, G. Schuler, R. M. Steinman, and N. Bhardwaj, "Improved methods for the generation of dendritic cells from nonproliferating progenitors in human blood," Journal of Immunological Methods, vol. 196, no. 2, pp. 121-135, 1996.

[38] F. Sallusto and A. Lanzavecchia, "Efficient presentation of soluble antigen by cultured human dendritic cells is maintained by granulocyte/macrophage colony-stimulating factor plus interleukin 4 and downregulated by tumor necrosis factor $\alpha$, The Journal of Experimental Medicine, vol. 179, no. 4, pp. 1109-1118, 1994.

[39] N. Romani, D. Reider, M. Heuer, et al., "Generation of mature dendritic cells from human blood. An improved method with special regard to clinical applicability," Journal of Immunological Methods, vol. 196, no. 2, pp. 137-151, 1996.

[40] M.-C. Rissoan, V. Soumelis, N. Kadowaki, et al., "Reciprocal control of T helper cell and dendritic cell differentiation," Science, vol. 283, no. 5405, pp. 1183-1186, 1999.

[41] G. Grouard, M.-C. Rissoan, L. Filgueira, I. Durand, J. Banchereau, and Y.-J. Liu, "The enigmatic plasmacytoid T cells develop into dendritic cells with interleukin (IL)-3 and CD40-ligand," The Journal of Experimental Medicine, vol. 185, no. 6, pp. 1101-1111, 1997.

[42] M. Salio, M. Cella, W. Vermi, et al., "Plasmacytoid dendritic cells prime IFN- $\gamma$-secreting melanoma-specific CD8 lymphocytes and are found in primary melanoma lesions," European Journal of Immunology, vol. 33, no. 4, pp. 10521062, 2003.

[43] E. Hartmann, B. Wollenberg, S. Rothenfusser, et al., "Identification and functional analysis of tumor-infiltrating plasmacytoid dendritic cells in head and neck cancer," Cancer Research, vol. 63, no. 19, pp. 6478-6487, 2003.

[44] W. Zou, V. Machelon, A. Coulomb-L'Hermin, et al., "Stromal-derived factor-1 in human tumors recruits and alters the function of plasmacytoid precursor dendritic cells," Nature Medicine, vol. 7, no. 12, pp. 1339-1346, 2001.

[45] I. Treilleux, J.-Y. Blay, N. Bendriss-Vermare, et al., "Dendritic cell infiltration and prognosis of early stage breast cancer," Clinical Cancer Research, vol. 10, no. 22, pp. 7466-7474, 2004.

[46] F. Palamara, S. Meindl, M. Holcmann, P. Lührs, G. Stingl, and M. Sibilia, "Identification and characterization of pDClike cells in normal mouse skin and melanomas treated with imiquimod," The Journal of Immunology, vol. 173, no. 5, pp. 3051-3061, 2004.

[47] B. J. Weigel, N. Nath, P. A. Taylor, et al., "Comparative analysis of murine marrow-derived dendritic cells generated by Flt3L or GM-CSF/IL-4 and matured with immune stimulatory agents on the in vivo induction of antileukemia responses," Blood, vol. 100, no. 12, pp. 4169-4176, 2002. 
[48] A. E. Morelli and A. W. Thomson, "Tolerogenic dendritic cells and the quest for transplant tolerance," Nature Reviews Immunology, vol. 7, no. 8, pp. 610-621, 2007.

[49] F. Fallarino, C. Asselin-Paturel, C. Vacca, et al., "Murine plasmacytoid dendritic cells initiate the immunosuppressive pathway of tryptophan catabolism in response to CD200 receptor engagement," The Journal of Immunology, vol. 173, no. 6, pp. 3748-3754, 2004.

[50] M. Colonna, G. Trinchieri, and Y.-J. Liu, "Plasmacytoid dendritic cells in immunity," Nature Immunology, vol. 5, no. 12, pp. 1219-1226, 2004.

[51] S. M. M. Haeryfar, "The importance of being a pDC in antiviral immunity: the IFN mission versus Ag presentation?" Trends in Immunology, vol. 26, no. 6, pp. 311-317, 2005.

[52] K. McKenna, A.-S. Beignon, and N. Bhardwaj, "Plasmacytoid dendritic cells: linking innate and adaptive immunity," Journal of Virology, vol. 79, no. 1, pp. 17-27, 2005.

[53] Y.-J. Liu, "Dendritic cell subsets and lineages, and their functions in innate and adaptive immunity," Cell, vol. 106, no. 3, pp. 259-262, 2001.

[54] B. Pulendran, J. L. Smith, G. Caspary, et al., "Distinct dendritic cell subsets differentially regulate the class of immune response in vivo," Proceedings of the National Academy of Sciences of the United States of America, vol. 96, no. 3, pp. 1036-1041, 1999.

[55] E. Maraskovsky, K. Brasel, M. Teepe, et al., "Dramatic increase in the numbers of functionally mature dendritic cells in Flt3 ligand-treated mice: multiple dendritic cell subpopulations identified," The Journal of Experimental Medicine, vol. 184, no. 5, pp. 1953-1962, 1996.

[56] B. Pulendran, J. Lingappa, M. K. Kennedy, et al., "Developmental pathways of dendritic cells in vivo: distinct function, phenotype, and localization of dendritic cell subsets in FLT3 ligand-treated mice," The Journal of Immunology, vol. 159, no. 5, pp. 2222-2231, 1997.

[57] E. Maraskovsky, E. Daro, E. Roux, et al., "In vivo generation of human dendritic cell subsets by Flt3 ligand," Blood, vol. 96, no. 3, pp. 878-884, 2000.

[58] B. Pulendran, J. Banchereau, S. Burkeholder, et al., "Flt3ligand and granulocyte colony-stimulating factor mobilize distinct human dendritic cell subsets in vivo," The Journal of Immunology, vol. 165, no. 1, pp. 566-572, 2000.

[59] M. R. Shurin, P. P. Pandharipande, T. D. Zorina, et al., "FLT3 ligand induces the generation of functionally active dendritic cells in mice," Cellular Immunology, vol. 179, no. 2, pp. 174184, 1997.

[60] K. Brasel, T. De Smedt, J. L. Smith, and C. R. Maliszewski, "Generation of murine dendritic cells from flt3-ligandsupplemented bone marrow cultures," Blood, vol. 96, no. 9, pp. 3029-3039, 2000.

[61] M. Gilliet, A. Boonstra, C. Paturel, et al., "The development of murine plasmacytoid dendritic cell precursors is differentially regulated by FLT3-ligand and granulocyte/macrophage colony-stimulating factor," The Journal of Experimental Medicine, vol. 195, no. 7, pp. 953-958, 2002.

[62] B. Fancke, M. Suter, H. Hochrein, and M. O'Keeffe, "MCSF: a novel plasmacytoid and conventional dendritic cell poietin," Blood, vol. 111, no. 1, pp. 150-159, 2008.

[63] S. Blomberg, M.-L. Eloranta, M. Magnusson, G. V. Alm, and L. Rönnblom, "Expression of the markers BDCA-2 and BDCA- 4 and production of interferon- $\alpha$ by plasmacytoid dendritic cells in systemic lupus erythematosus," Arthritis and Rheumatism, vol. 48, no. 9, pp. 2524-2532, 2003.
[64] A. Krug, A. R. French, W. Barchet, et al., "TLR9-dependent recognition of MCMV by IPC and DC generates coordinated cytokine responses that activate antiviral NK cell function," Immunity, vol. 21, no. 1, pp. 107-119, 2004.

[65] U. O’Doherty, M. Peng, S. Gezelter, et al., "Human blood contains two subsets of dendritic cells, one immunologically mature and the other immature," Immunology, vol. 82, no. 3, pp. 487-493, 1994.

[66] R. V. Sorg, G. Kögler, and P. Wernet, "Identification of cord blood dendritic cells as an immature CD11c- population," Blood, vol. 93, no. 7, pp. 2302-2307, 1999.

[67] Y. Kamogawa-Schifter, J. Ohkawa, S. Namiki, N. Arai, K.-I. Arai, and Y. Liu, "Ly49Q defines 2 pDC subsets in mice," Blood, vol. 105, no. 7, pp. 2787-2792, 2005.

[68] B. Blom, S. Ho, S. Antonenko, and Y.-J. Liu, "Generation of interferon $\alpha$-producing predendritic cell (pre-DC)2 from human $\mathrm{CD}_{3} 4^{+}$hematopoietic stem cells," The Journal of Experimental Medicine, vol. 192, no. 12, pp. 1785-1796, 2000.

[69] M. Cella, D. Jarrossay, F. Facchetti, et al., "Plasmacytoid monocytes migrate to inflamed lymph nodes and produce large amounts of type I interferon," Nature Medicine, vol. 5, no. 8, pp. 919-923, 1999.

[70] G. Penna, M. Vulcano, S. Sozzani, and L. Adorini, "Differential migration behavior and chemokine production by myeloid and plasmacytoid dendritic cells," Human Immunology, vol. 63, no. 12, pp. 1164-1171, 2002.

[71] A. Blasius, W. Vermi, A. Krug, F. Facchetti, M. Cella, and M. Colonna, "A cell-surface molecule selectively expressed on murine natural interferon-producing cells that blocks secretion of interferon-alpha," Blood, vol. 103, no. 11, pp. 4201-4206, 2004.

[72] C. Asselin-Paturel, G. Brizard, J.-J. Pin, F. Brière, and G. Trinchieri, "Mouse strain differences in plasmacytoid dendritic cell frequency and function revealed by a novel monoclonal antibody," The Journal of Immunology, vol. 171, no. 12, pp. 6466-6477, 2003.

[73] H. Yoneyama, K. Matsuno, Y. Zhang, et al., "Evidence for recruitment of plasmacytoid dendritic cell precursors to inflamed lymph nodes through high endothelial venules," International Immunology, vol. 16, no. 7, pp. 915-928, 2004.

[74] G. Penna, S. Sozzani, and L. Adorini, "Cutting edge: selective usage of chemokine receptors by plasmacytoid dendritic cells," The Journal of Immunology, vol. 167, no. 4, pp. 18621866, 2001.

[75] W. Vermi, R. Bonecchi, F. Facchetti, et al., "Recruitment of immature plasmacytoid dendritic cells (plasmacytoid monocytes) and myeloid dendritic cells in primary cutaneous melanomas," The Journal of Pathology, vol. 200, no. 2, pp. 255-268, 2003.

[76] C. Bangert, J. Friedl, G. Stary, G. Stingl, and T. Kopp, "Immunopathologic features of allergic contact dermatitis in humans: participation of plasmacytoid dendritic cells in the pathogenesis of the disease?" Journal of Investigative Dermatology, vol. 121, no. 6, pp. 1409-1418, 2003.

[77] P. Fitzgerald-Bocarsly, M. Feldman, M. Mendelsohn, S. Curl, and C. Lopez, "Human mononuclear cells which produce interferon-alpha during NK(HSV-FS) assays are HLA-DR positive cells distinct from cytolytic natural killer effectors," Journal of Leukocyte Biology, vol. 43, no. 4, pp. 323-334, 1988.

[78] M. Cella, M. Salio, Y. Sakakibara, H. Langen, I. Julkunen, and A. Lanzavecchia, "Maturation, activation, and protection of dendritic cells induced by double-stranded RNA," The Journal of Experimental Medicine, vol. 189, no. 5, pp. 821829, 1999. 
[79] M. Dalod, T. P. Salazar-Mather, L. Malmgaard, et al., "Interferon $\alpha / \beta$ and interleukin 12 responses to viral infections: pathways regulating dendritic cell cytokine expression in vivo," The Journal of Experimental Medicine, vol. 195, no. 4, pp. 517-528, 2002.

[80] M. Dalod, T. Hamilton, R. Salomon, et al., "Dendritic cell responses to early murine cytomegalovirus infection: subset functional specialization and differential regulation by interferon $\alpha / \beta$," The Journal of Experimental Medicine, vol. 197, no. 7, pp. 885-898, 2003.

[81] A. J. Sadler and B. R. G. Williams, "Interferon-inducible antiviral effectors," Nature Reviews Immunology, vol. 8, no. 7, pp. 559-568, 2008.

[82] M. Montoya, G. Schiavoni, F. Mattei, et al., “Type I interferons produced by dendritic cells promote their phenotypic and functional activation," Blood, vol. 99, no. 9, pp. 32633271, 2002.

[83] A. Le Bon, N. Etchart, C. Rossmann, et al., "Cross-priming of $\mathrm{CD}^{+}$T cells stimulated by virus-induced type I interferon," Nature Immunology, vol. 4, no. 10, pp. 1009-1015, 2003.

[84] A. Le Bon, G. Schiavoni, G. D’Agostino, I. Gresser, F. Belardelli, and D. F. Tough, "Type I interferons potently enhance humoral immunity and can promote isotype switching by stimulating dendritic cells in vivo," Immunity, vol. 14, no. 4, pp. 461-470, 2001.

[85] O. Duramad, K. L. Fearon, J. H. Chan, et al., "IL-10 regulates plasmacytoid dendritic cell response to CpG-containing immunostimulatory sequences," Blood, vol. 102, no. 13, pp. 4487-4492, 2003.

[86] A. Krug, S. Rothenfusser, V. Hornung, et al., "Identification of $\mathrm{CpG}$ oligonucleotide sequences with high induction of IFN- $\alpha / \beta$ in plasmacytoid dendritic cells," European Journal of Immunology, vol. 31, no. 7, pp. 2154-2163, 2001.

[87] M. Schnurr, T. Toy, A. Shin, G. Hartmann, S. Rothenfusser, and J. Soellner, "Role of adenosine receptors in regulating chemotaxis and cytokine production of plasmacytoid dendritic cells," Blood, vol. 103, no. 4, pp. 1391-1397, 2004.

[88] N. J. Megjugorac, H. A. Young, S. B. Amrute, S. L. Olshalsky, and P. Fitzgerald-Bocarsly, "Virally stimulated plasmacytoid dendritic cells produce chemokines and induce migration of T and NK cells," Journal of Leukocyte Biology, vol. 75, no. 3, pp. 504-514, 2004.

[89] B. Piqueras, J. Connolly, H. Freitas, A. K. Palucka, and J. Banchereau, "Upon viral exposure, myeloid and plasmacytoid dendritic cells produce 3 waves of distinct chemokines to recruit immune effectors," Blood, vol. 107, no. 7, pp. 26132618, 2006.

[90] S. V. Kotenko, G. Gallagher, V. V. Baurin, et al., "IFN$\lambda s$ mediate antiviral protection through a distinct class II cytokine receptor complex," Nature Immunology, vol. 4, no. 1, pp. 69-77, 2003.

[91] P. Sheppard, W. Kindsvogel, W. Xu, et al., "IL-28, IL-29 and their class II cytokine receptor IL-28R," Nature Immunology, vol. 4, no. 1, pp. 63-68, 2003.

[92] K. Ozato, P. Tailor, and T. Kubota, "The interferon regulatory factor family in host defense: mechanism of action," The Journal of Biological Chemistry, vol. 282, no. 28, pp. 2006520069, 2007.

[93] A. Izaguirre, B. J. Barnes, S. Amrute, et al., "Comparative analysis of IRF and IFN-alpha expression in human plasmacytoid and monocyte-derived dendritic cells," Journal of Leukocyte Biology, vol. 74, no. 6, pp. 1125-1138, 2003.
[94] P. Tailor, T. Tamura, and K. Ozato, "IRF family proteins and type I interferon induction in dendritic cells," Cell Research, vol. 16, no. 2, pp. 134-140, 2006.

[95] C. A. Janeway Jr. and R. Medzhitov, "Innate immune recognition," Annual Review of Immunology, vol. 20, no. 1, pp. 197-216, 2002.

[96] K. Takeda, T. Kaisho, and S. Akira, "Toll-like receptors," Annual Review of Immunology, vol. 21, pp. 335-376, 2003.

[97] H. Hemmi, T. Kaisho, O. Takeuchi, et al., "Small-antiviral compounds activate immune cells via the TLR7 MyD88dependent signaling pathway," Nature Immunology, vol. 3, no. 2, pp. 196-200, 2002.

[98] A. Krug, A. Towarowski, S. Britsch, et al., "Toll-like receptor expression reveals CpG DNA as a unique microbial stimulus for plasmacytoid dendritic cells which synergizes with $\mathrm{Cd} 40$ ligand to induce high amounts of IL-12," European Journal of Immunology, vol. 31, no. 10, pp. 3026-3037, 2001.

[99] F. Heil, P. Ahmad-Nejad, H. Hemmi, et al., "The Toll-like receptor 7 (TLR7)-specific stimulus loxoribine uncovers a strong relationship within the TLR7, 8 and 9 subfamily," European Journal of Immunology, vol. 33, no. 11, pp. 29872997, 2003.

[100] E. Latz, A. Schoenemeyer, A. Visintin, et al., "TLR9 signals after translocating from the ER to CpG DNA in the lysosome," Nature Immunology, vol. 5, no. 2, pp. 190-198, 2004.

[101] T. Kawai, S. Sato, K. J. Ishii, et al., "Interferon- $\alpha$ induction through Toll-like receptors involves a direct interaction of IRF7 with MyD88 and TRAF6," Nature Immunology, vol. 5, no. 10, pp. 1061-1068, 2004.

[102] C. L. Ahonen, S. J. Gibson, R. M. Smith, et al., "Dendritic cell maturation and subsequent enhanced T-cell stimulation induced with the novel synthetic immune response modifier R-848," Cellular Immunology, vol. 197, no. 1, pp. 62-72, 1999.

[103] T. Ito, R. Amakawa, T. Kaisho, et al., "Interferon- $\alpha$ and interleukin-12 are induced differentially by Toll-like receptor 7 ligands in human blood dendritic cell subsets," The Journal of Experimental Medicine, vol. 195, no. 11, pp. 1507-1512, 2002.

[104] K. Loré, M. R. Betts, J. M. Brenchley, et al., "Tolllike receptor ligands modulate dendritic cells to augment cytomegalovirus- and HIV-1-specific T cell responses," The Journal of Immunology, vol. 171, no. 8, pp. 4320-4328, 2003.

[105] F. J. Barrat, T. Meeker, J. Gregorio, et al., "Nucleic acids of mammalian origin can act as endogenous ligands for Tolllike receptors and may promote systemic lupus erythematosus," The Journal of Experimental Medicine, vol. 202, no. 8, pp. 1131-1139, 2005.

[106] A. M. Krieg, "Therapeutic potential of Toll-like receptor 9 activation," Nature Reviews Drug Discovery, vol. 5, no. 6, pp. 471-484, 2006.

[107] A. M. Krieg, "Development of TLR9 agonists for cancer therapy," The Journal of Clinical Investigation, vol. 117, no. 5, pp. 1184-1194, 2007.

[108] Y. M. Murad, T. M. Clay, H. K. Lyerly, and M. A. Morse, "CPG-7909 (PF-3512676, ProMune ${ }^{\circledR}$ ): Toll-like receptor9 agonist in cancer therapy," Expert Opinion on Biological Therapy, vol. 7, no. 8, pp. 1257-1266, 2007.

[109] Y. Lou, C. Liu, G. J. Kim, Y.-J. Liu, P. Hwu, and G. Wang, "Plasmacytoid dendritic cells synergize with myeloid dendritic cells in the induction of antigen-specific antitumor immune responses," The Journal of Immunology, vol. 178, no. 3, pp. 1534-1541, 2007. 
[110] O. Preynat-Seauve, P. Schuler, E. Contassot, F. Beermann, B. Huard, and L. E. French, "Tumor-infiltrating dendritic cells are potent antigen-presenting cells able to activate T cells and mediate tumor rejection," The Journal of Immunology, vol. 176, no. 1, pp. 61-67, 2006.

[111] A. P. Vicari, C. Chiodoni, C. Vaure, et al., "Reversal of tumorinduced dendritic cell paralysis by $\mathrm{CpG}$ immunostimulatory oligonucleotide and anti-interleukin 10 receptor antibody," The Journal of Experimental Medicine, vol. 196, no. 4, pp. 541-549, 2002.

[112] M. Pashenkov, G. Goëss, C. Wagner, et al., "Phase II trial of a toll-like receptor 9-activating oligonucleotide in patients with metastatic melanoma," Journal of Clinical Oncology, vol. 24, no. 36, pp. 5716-5724, 2006.

[113] N. Kadowaki, S. Antonenko, J. Y.-N. Lau, and Y.-J. Liu, "Natural interferon $\alpha / \beta$-producing cells link innate and adaptive immunity," The Journal of Experimental Medicine, vol. 192, no. 2, pp. 219-226, 2000.

[114] C. A. Biron, "Interferons $\alpha$ and $\beta$ as immune regulators-a new look," Immunity, vol. 14, no. 6, pp. 661-664, 2001.

[115] K. Hoebe, E. Janssen, and B. Beutler, "The interface between innate and adaptive immunity," Nature Immunology, vol. 5, no. 10, pp. 971-974, 2004.

[116] G. Trinchieri, D. Santoli, R. R. Dee, and B. B. Knowles, "Anti-viral activity induced by culturing lymphocytes with tumor-derived or virus-transformed cells. Identification of the anti-viral activity as interferon and characterization of the human effector lymphocyte subpopulation," The Journal of Experimental Medicine, vol. 147, no. 5, pp. 1299-1313, 1978.

[117] S. Bandyopadhyay, B. Perussia, G. Trinchieri, D. S. Miller, and S. E. Starr, "Requirement for HLA-DR ${ }^{+}$accessory cells in natural killing of cytomegalovirus-infected fibroblasts," The Journal of Experimental Medicine, vol. 164, no. 1, pp. 180195, 1986.

[118] M. Cella, F. Facchetti, A. Lanzavecchia, and M. Colonna, "Plasmacytoid dendritic cells activated by influenza virus and CD40L drive a potent $\mathrm{T}_{\mathrm{H}^{1}}$ polarization," Nature Immunology, vol. 1, no. 4, pp. 305-310, 2000.

[119] A. Langenkamp, K. Nagata, K. Murphy, L. Wu, A. Lanzavecchia, and F. Sallusto, "Kinetics and expression patterns of chemokine receptors in human $\mathrm{CD} 4^{+} \mathrm{T}$ lymphocytes primed by myeloid or plasmacytoid dendritic cells," European Journal of Immunology, vol. 33, no. 2, pp. 474-482, 2003.

[120] D. Agnello, C. S. R. Lankford, J. Bream, et al., "Cytokines and transcription factors that regulate $\mathrm{T}$ helper cell differentiation: new players and new insights," Journal of Clinical Immunology, vol. 23, no. 3, pp. 147-161, 2003.

[121] F. Belardelli and I. Gresser, "The neglected role of type I interferon in the T-cell response: implications for its clinical use," Immunology Today, vol. 17, no. 8, pp. 369-372, 1996.

[122] M. Mohty, A. Vialle-Castellano, J. A. Nunes, D. Isnardon, D. Olive, and B. Gaugler, "IFN- $\alpha$ skews monocyte differentiation into toll-like receptor 7-expressing dendritic cells with potent functional activities," The Journal of Immunology, vol. 171, no. 7, pp. 3385-3393, 2003.

[123] F. Belardelli, M. Ferrantini, E. Proietti, and J. M. Kirkwood, "Interferon-alpha in tumor immunity and immunotherapy," Cytokine \& Growth Factor Reviews, vol. 13, no. 2, pp. 119134, 2002.

[124] M. Ferrantini and F. Belardelli, "Gene therapy of cancer with interferon: lessons from tumor models and perspectives for clinical applications," Seminars in Cancer Biology, vol. 10, no. 2, pp. 145-157, 2000.

[125] R. Baccala, K. Hoebe, D. H. Kono, B. Beutler, and A. N. Theofilopoulos, "TLR-dependent and TLR-independent pathways of type I interferon induction in systemic autoimmunity," Nature Medicine, vol. 13, no. 5, pp. 543-551, 2007.

[126] A. Dzionek, Y. Inagaki, K. Okawa, et al., "Plasmacytoid dendritic cells: from specific surface markers to specific cellular functions," Human Immunology, vol. 63, no. 12, pp. 1133-1148, 2002.

[127] T. Ito, R. Amakawa, M. Inaba, et al., "Plasmacytoid dendritic cells regulate Th cell responses through OX40 ligand and type I IFNs," The Journal of Immunology, vol. 172, no. 7, pp. 42534259, 2004.

[128] J.-F. Fonteneau, M. Larsson, A.-S. Beignon, et al., "Human immunodeficiency virus type 1 activates plasmacytoid dendritic cells and concomitantly induces the bystander maturation of myeloid dendritic cells," Journal of Virology, vol. 78, no. 10, pp. 5223-5232, 2004.

[129] J.-F. Fonteneau, M. Gilliet, M. Larsson, et al., "Activation of influenza virus-specific $\mathrm{CD}^{+}$and $\mathrm{CD}^{+} \mathrm{T}$ cells: a new role for plasmacytoid dendritic cells in adaptive immunity," Blood, vol. 101, no. 9, pp. 3520-3526, 2003.

[130] K. Mahnke, Y. Qian, J. Knop, and A. H. Enk, "Induction of $\mathrm{CD} 4^{+} / \mathrm{CD} 25^{+}$regulatory $\mathrm{T}$ cells by targeting of antigens to immature dendritic cells," Blood, vol. 101, no. 12, pp. 48624869, 2003.

[131] M. Salio, M. J. Palmowski, A. Atzberger, I. F. Hermans, and V. Cerundolo, "CpG-matured murine plasmacytoid dendritic cells are capable of in vivo priming of functional CD8 T cell responses to endogenous but not exogenous antigens," The Journal of Experimental Medicine, vol. 199, no. 4, pp. 567579, 2004.

[132] J. A. Shah, P. A. Darrah, D. R. Ambrozak, et al., "Dendritic cells are responsible for the capacity of CpG oligodeoxynucleotides to act as an adjuvant for protective vaccine immunity against Leishmania major in mice," The Journal of Experimental Medicine, vol. 198, no. 2, pp. 281-291, 2003.

[133] B. Pulendran and R. A. Seder, "Host-pathogen interactions in the 21st century," Current Opinion in Immunology, vol. 17, no. 4, pp. 335-337, 2005.

[134] M. A. Degli-Esposti and M. J. Smyth, "Close encounters of different kinds: dendritic cells and NK cells take centre stage," Nature Reviews Immunology, vol. 5, no. 2, pp. 112-124, 2005.

[135] C. Pasare and R. Medzhitov, "Toll-like receptors: linking innate and adaptive immunity," Advances in Experimental Medicine and Biology, vol. 560, pp. 11-18, 2005.

[136] C. Münz, R. M. Steinman, and S. Fujii, "Dendritic cell maturation by innate lymphocytes: coordinated stimulation of innate and adaptive immunity," The Journal of Experimental Medicine, vol. 202, no. 2, pp. 203-207, 2005.

[137] K. Evel-Kabler and S.-Y. Chen, "Dendritic cell-based tumor vaccines and antigen presentation attenuators," Molecular Therapy, vol. 13, no. 5, pp. 850-858, 2006.

[138] H. J. Bontkes, J. J. Ruizendaal, D. Kramer, C. J. L. M. Meijer, and E. Hooijberg, "Plasmacytoid dendritic cells are present in cervical carcinoma and become activated by human papillomavirus type 16 virus-like particles," Gynecologic Oncology, vol. 96, no. 3, pp. 897-901, 2005.

[139] A. Faith, E. Peek, J. McDonald, et al., "Plasmacytoid dendritic cells from human lung cancer draining lymph nodes induce Tc1 responses," American Journal of Respiratory Cell and Molecular Biology, vol. 36, no. 3, pp. 360-367, 2007. 
[140] A. S. Lonsdorf, H. Kuekrek, B. V. Stern, B. O. Boehm, P. V. Lehmann, and M. Tary-Lehmann, "Intratumor CpGoligodeoxynucleotide injection induces protective antitumor T cell immunity," The Journal of Immunology, vol. 171, no. 8, pp. 3941-3946, 2003.

[141] D. N. Sauder, "Imiquimod: modes of action," British Journal of Dermatology, vol. 149, supplement 66, pp. 5-8, 2003.

[142] R. L. Paquette, N. C. Hsu, S. M. Kiertscher, et al., "Interferon$\alpha$ and granulocyte-macrophage colony-stimulating factor differentiate peripheral blood monocytes into potent antigen-presenting cells," Journal of Leukocyte Biology, vol. 64, no. 3, pp. 358-367, 1998.

[143] T. Luft, K. C. Pang, E. Thomas, et al., “Type I IFNs enhance the terminal differentiation of dendritic cells," The Journal of Immunology, vol. 161, no. 4, pp. 1947-1953, 1998.

[144] S. M. Santini, C. Lapenta, M. Logozzi, et al., "Type I interferon as a powerful adjuvant for monocyte-derived dendritic cell development and activity in vitro and in $\mathrm{Hu}$ PBL-SCID mice," The Journal of Experimental Medicine, vol. 191, no. 10, pp. 1777-1788, 2000.

[145] P. Blanco, A. K. Palucka, M. Gill, V. Pascual, and J. Banchereau, "Induction of dendritic cell differentiation by IFN- $\alpha$ in systemic lupus erythematosus," Science, vol. 294, no. 5546, pp. 1540-1543, 2001.

[146] D. Gabrilovich, "Mechanisms and functional significance of tumour-induced dendritic-cell defects," Nature Reviews Immunology, vol. 4, no. 12, pp. 941-952, 2004.

[147] S. Benkő, Z. Magyarics, A. Szabó, and É. Rajnavölgyi, "Dendritic cell subtypes as primary targets of vaccines: the emerging role and cross-talk of pattern recognition receptors," Biological Chemistry, vol. 389, no. 5, pp. 469-485, 2008. 


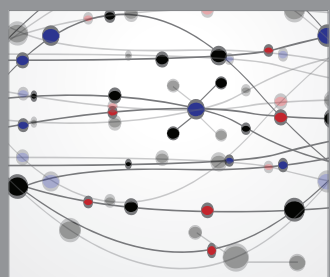

The Scientific World Journal
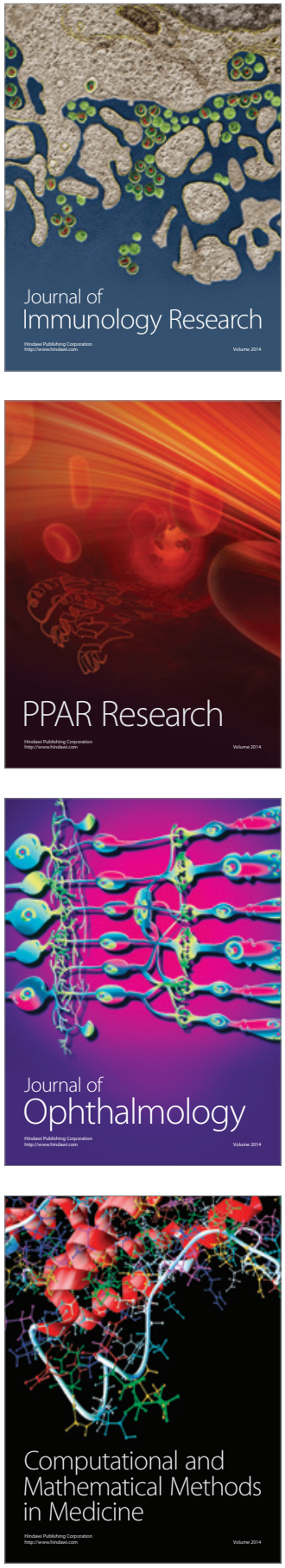

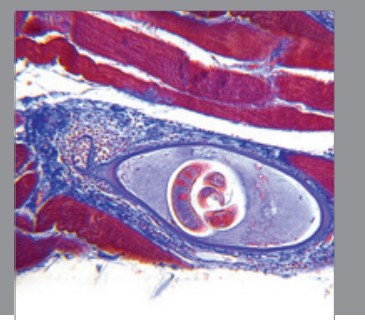

Gastroenterology

Research and Practice
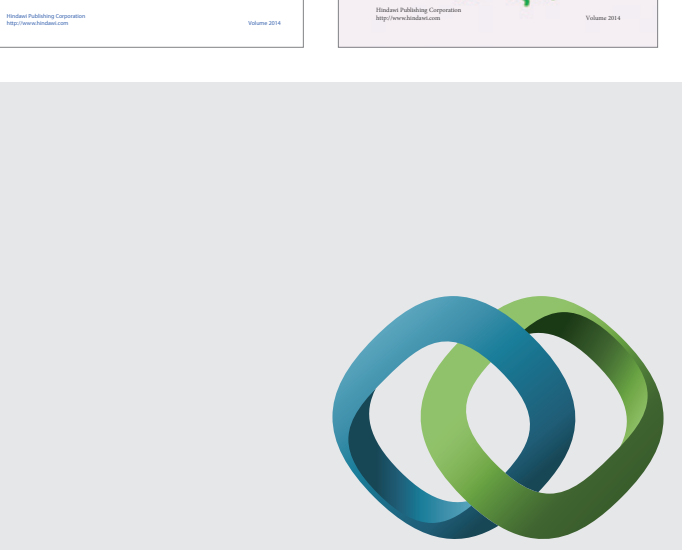

\section{Hindawi}

Submit your manuscripts at

http://www.hindawi.com
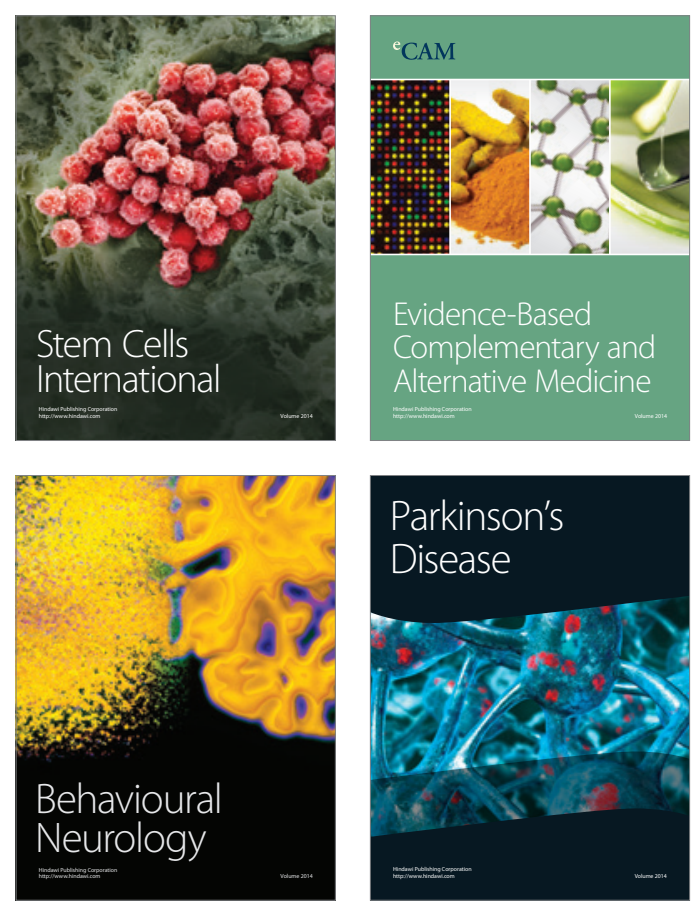

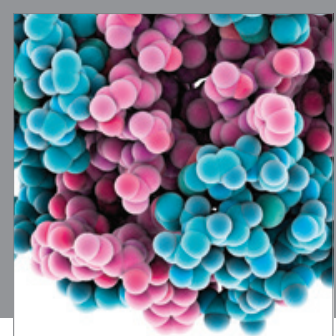

Journal of
Diabetes Research

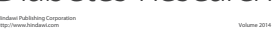

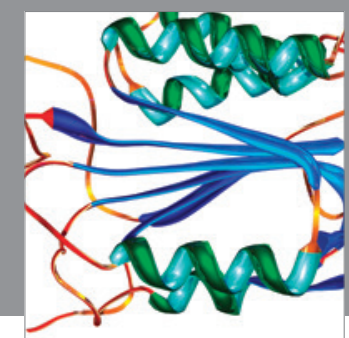

Disease Markers
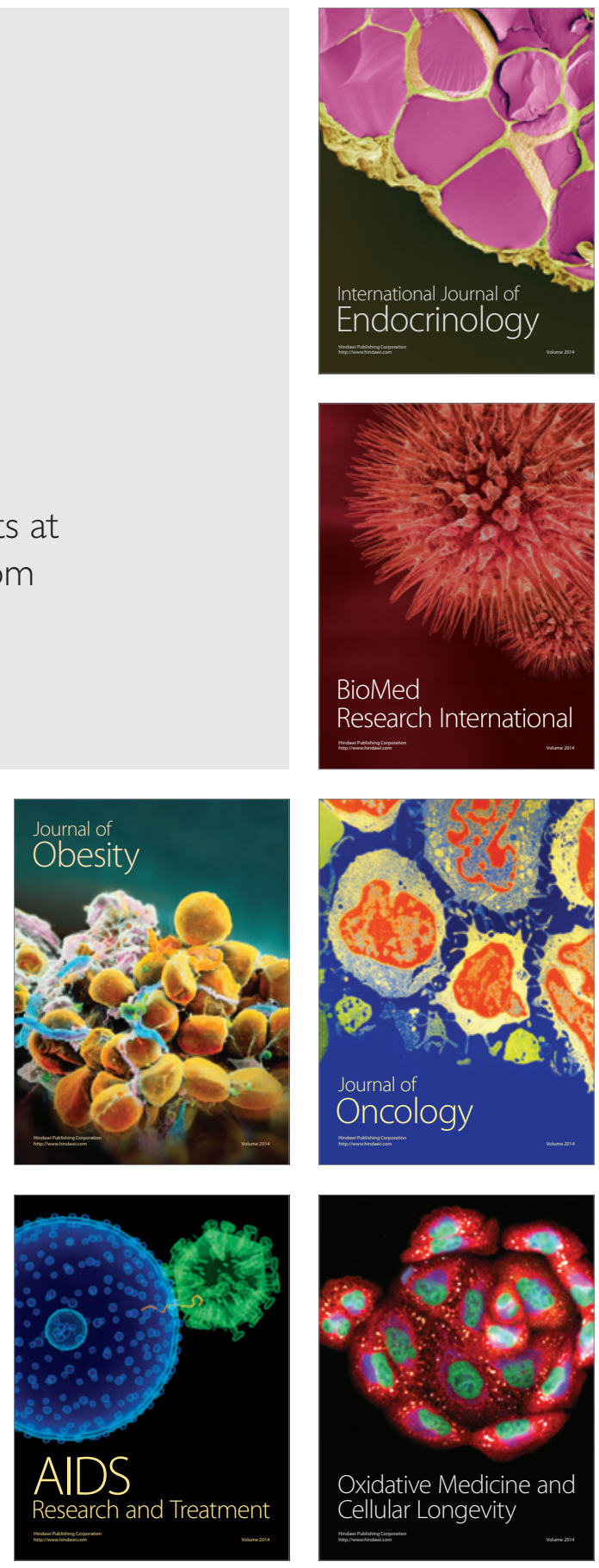